\title{
História Breve dos Pigmentos 1 - Da Arte do Homem Pré-histórico
}

\author{
J O Ã O M. PEIXOTO C A B R A L *
}

Há muitos milénios que os homens vềm usando colorantes para decorar objectos e habitações. Começaram por recorrer a produtos naturais mas, pouco a pouco, passaram a servir-se também de materiais sintéticos que iam descobrindo e produzindo. Para isso contribuíram na Antiguidade, técnicos diversos, alquimistas $\mathrm{e}$ médicos. Com o nascimento da química moderna, no séc. XVIII, tal contributo passou a ser dado por químicos, às vezes em consequência de descobertas importantes na sua própria disciplina. Nesta série de artigos faz-se uma descricão dos referidos produtos e materiais, em particular dos pigmentos.

$\mathrm{O}$ presente artigo diz respeito aos pigmentos utilizados pelos artistas pré-históricos e, atendendo à grande importância que a arte pré-histórica adquiriu em Portugal com a descoberta das gravuras rupestres de Foz Côa, inclui a título excepcional um esboco sobre as suas técnicas de pintura.

\section{INTRODUÇÃO}

Poucas áreas haverá na Química tão intimamente relacionadas com a Arte, em particular com a Pintura, como a dos materiais colorantes. Por sua vez, nunca a relação desta área com a Pintura terá sido tão estreita como no decurso das três primeiras décadas do séc. XIX, durante as quais as paletas dos pintores foram sendo consideravelmente enriquecidas, em resultado da descoberta de novos pigmentos por químicos, a um ritmo e com um impacto na técnica desses artistas verdadeiramente excepcionais. Um dos principais factores que contribuíram para isso foi o aparecimento em França, no último quartel do séc. XVIII, de uma nova química sistemática saída da revolução promovida por Lavoisier. Outro foi o enorme desenvolvimento que se verificou pouco tempo depois nos métodos de análise química, muito estimulado pela in- vestigação mineralógica. Outro ainda foi o rápido progresso realizado na investigação em química inorgânica, designadamente na química do crómio, do cádmio, do cobalto, do zinco, do cobre e do arsénio. Sobre esta matéria, porém, praticamente nada tem sido considerado no ensino da Química em Portugal, seja para tornar este ensino porventura mais atractivo, seja para mostrar aos alunos que a Química também tem contribuído para o progresso das Artes.

O presente trabalho tem por fim chamar a atenção dos professores de química do ensino secundário para a existência da referida relação e, além disso delinear um esboço da história desses materiais que lhes permita criar uma ideia satisfatória sobre a sua origem, natureza e usos. Note-se que a produção dos mais antigos materiais colorantes sintéticos tem as suas raízes firmadas nas tecnologias da Antiguidade, na Alquimia e na Medicina. Assim, parece razoável que nesse esboço sejam incluídos também os colorantes mais antigos, i.e., todos os anteriores ao nascimento da química moderna. Como o seu número é grande e o espaço disponível reduzido, isso obrigará a que o trabalho tenha de ser dividido em vários artigos.

Importa recordar que é costume classificar os materiais colorantes em dois grupos - corantes e pigmentos consoante a sua natureza (orgânica ou inorgânica) e o modo de aplicação. Os corantes são produtos orgânicos que se aplicam dissolvendo-os primeiro num meio adequado e, em seguida, imergindo nas soluções preparadas os objectos a tingir (caso dos textéis), ou assentando as soluções na superfície dos objectos que se pretende colorir (caso da pintura). A sua fixação à superfície destes é feita directamente, em resultado da ocorrência de uma interacção física ou química entre eles e os materiais de que são feitos os objectos. Pelo contrário, no caso dos pigmentos (produtos inorgânicos) tal interacção não se verifica e, por isso, estes colorantes só podem aplicar-se misturando-os previamente com uma substância aglutinante, onde não sejam solúveis, que assegure, por um lado, a coesão entre os seus grãos e, por outro, a sua aderência aos objectos. Note-se que há materiais colorantes que são produzidos fixando um dado corante num substrato inorgânico inerte, insolúvel, finamente dividido e semi-transparente, como o óxido de alumínio e o sulfato de cálcio. A tais materiais, que apesar de deverem a sua cor ao corante utilizado são aplicados da mesma maneira que os pigmentos, dá-se em língua inglesa o nome de lake pigments do qual a primeira palavra parece ter derivado do termo italiano lacca.

Neste trabalho ocupar-me-ei apenas dos pigmentos, com exclusão destes últimos. Os corantes e os pigmentos produzidos mediante a fixação de um corante num substrato inorgânico inerte, serão objecto de um trabalho posterior.

\section{PIGMENTOS UTILIZADOS PELOS ARTISTAS PRÉ-HISTÓRICOS}

Desconhece-se quando terá começado o homem a pintar. Sabe-se, no entanto, que na Europa alguns artistas da fase inicial do Paleolítico Superior, designadamente da época Aurignacense (Fig. 1), já faziam pinturas parietais de excelente qualida-

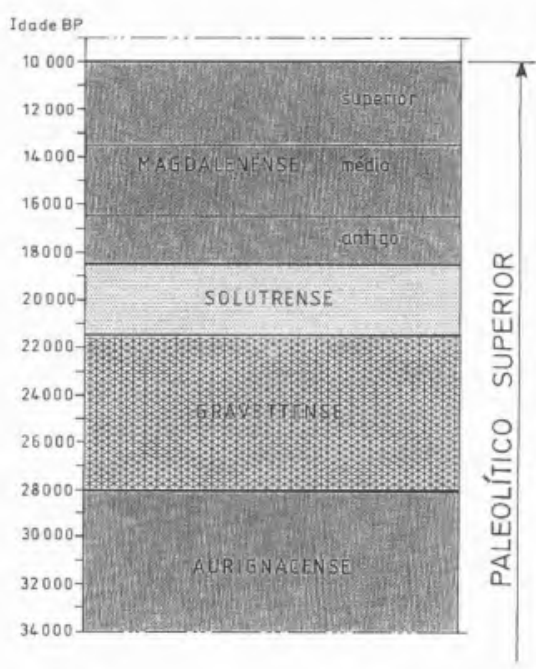

Fig. 1 - Crono-estratigrafia do Paleolítico Superior francês. As idades estão expressas em anos BP**. Adaptado de M. Lorblanchet (27), 242. 


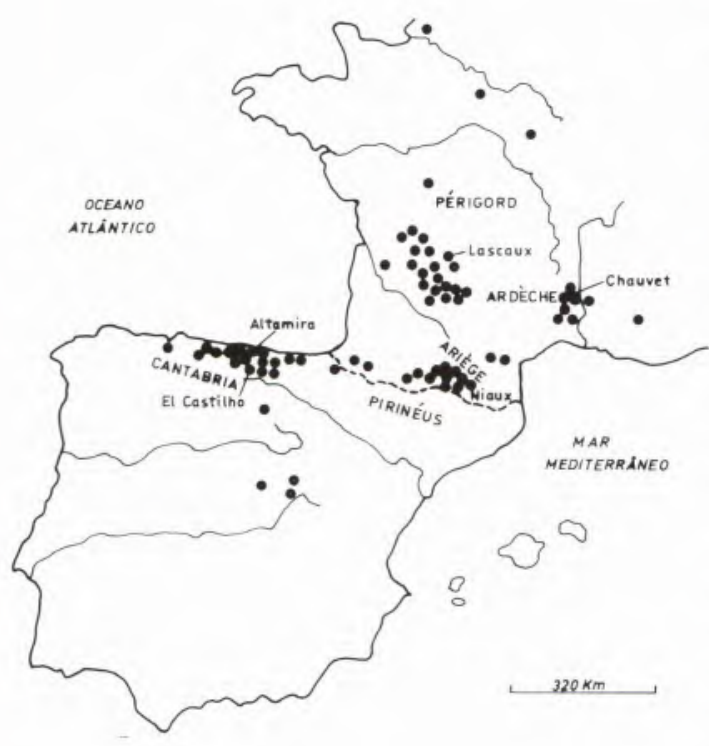

Fig. 2 - Lugares arqueológicos, com pintura paleolítica, mais importantes na Europa Ocidental.

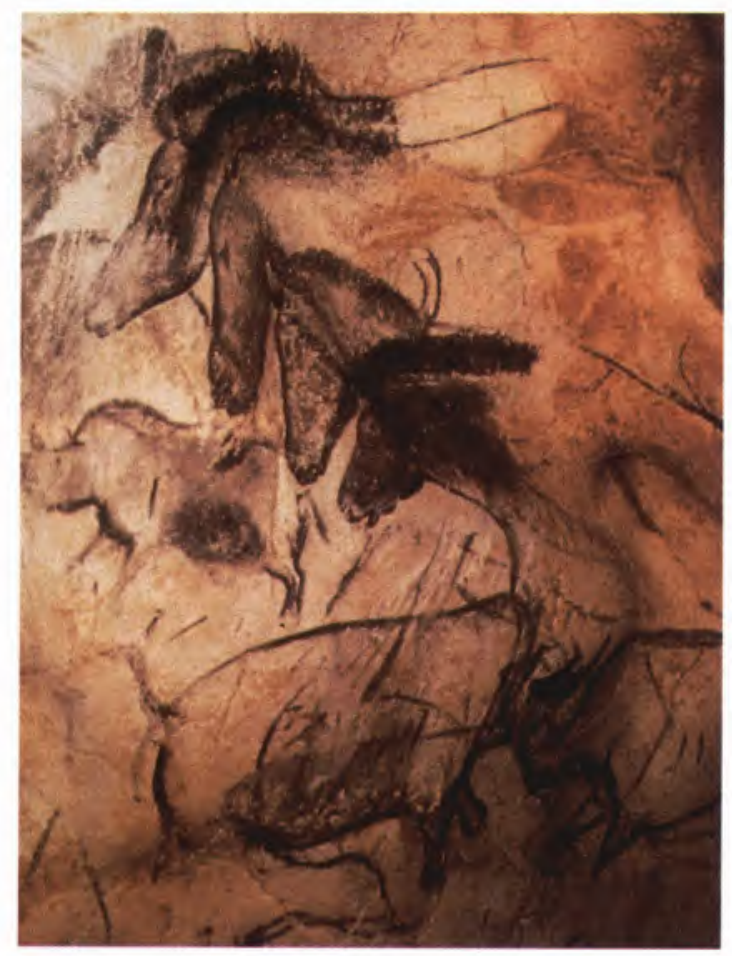

Fig. 3 - Cavalos e rinocerontes. Gruta de Chauvet-Pont-d'Arc. de. A demonstrá-lo estão as pinturas da recém-descoberta gruta de Chauvet-Pont-d'Arc [1] (Figs. 2 e 3), algumas das quais foram datadas directamente pelo ${ }^{14} \mathrm{C}$ dando resultados concordantes que colocam a sua realização à roda de 31000 BP [2]. São, por ora, as datas mais antigas obtidas para pinturas.

Tal descoberta teve consequências muito importantes, a principal das quais foi talvez a alteração das nossas concepções sobre o nascimento e evolução da arte. Na verdade, dessa época, a arte parietal que se conhecia não tinha a mesma qualidade que a da gruta de Chauvet e, por outro lado, havia testemunhos nas célebres grutas de Altamira e Lascaux, datados do Magdalenense médio (Fig. 1), de que a arte da pintura tinha atingido nesse tempo e nesses lugares um grau elevado de excelência. Admitia-se, por isso, que a gestação da arte teria durado vários milénios. Assim, a descoberta da gruta de Chauvet e das suas impressionantes pinturas, aliada à constatação de que elas tinham sido feitas há mais de 30000 anos, veio mostrar que esta ideia estava errada e que, durante o Paleolítico Superior, teria havido com toda a probabilidade diversos florescimentos, apogeus e declínios na arte da pintura, consoante as épocas e os lugares.

Além disso, a circunstância de actualmente não se conhecer nenhuma forma de arte antes do início do Paleolítico Superior e o facto de se terem encontrado vestígios da passagem do Homo Sapiens no Próximo Oriente, vestígios esses que, segundo os resultados da termoluminescência, têm uma idade superior a 90000 anos [3], vieram levantar a questão de saber se a arte já existiria durante esse intervalo de tempo ou se teria sido uma invenção tardia. O que parece mais lógico na situação presente, atendendo à descoberta atrás referida, é admitir que sim e também que possam existir formas elaboradas de arte que ainda não foram encontradas, ou que possam ter existido mas que não chegaram até nós por não se terem conservado.

\subsection{Primeiros passos na caracterização química da matéria pictural}

Os estudos de caracterização química da matéria pictural em pinturas pré-históricas foram iniciados em 1902, pouco depois da descoberta das grutas de Altamira (1878) e de Font-de-Gaume (1901), com os trabalhos de Moissan [4, 5] - prémio Nobel da Química, 1906 - relativos a esta última gruta e à gruta de La Mouthe. Moissan verificou que os pigmentos vermelho e negro, utilizados na execução das pinturas destas grutas (Fig. 4), eram constituidos por hematite $\left(\alpha \mathrm{Fe}_{2} \mathrm{O}_{3}\right)$ e óxido de manganês respectivamente, misturado com calcite e pequenos grãos de quartzo. Não encontrou, porém, nenhuns vestígios de materiais orgânicos que pudessem ter sido utilizados como aglutinantes. A resultados análogos chegou igualmente Courty [6], nesse mesmo ano, em análises que efectuou de pigmentos vermelhos $\mathrm{e}$ negros da gruta de Laugerie-Haute.

Mais tarde, em 1908, Cartailhac e o abade Breuil [7] referiram por sua vez, embora sem apresentarem nenhuma prova concreta para a sua

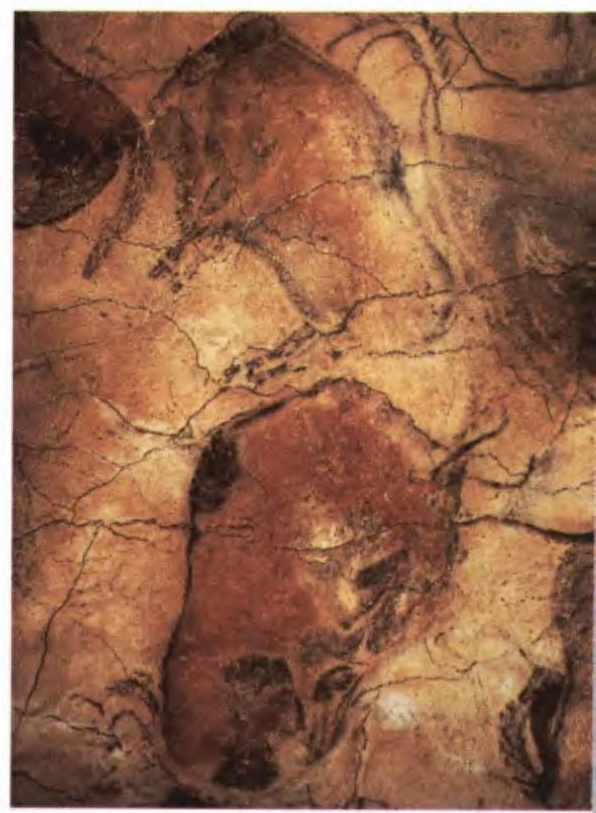

Fig. 4 - Bisontes policromados. Gruta de Altamira, tecto. 


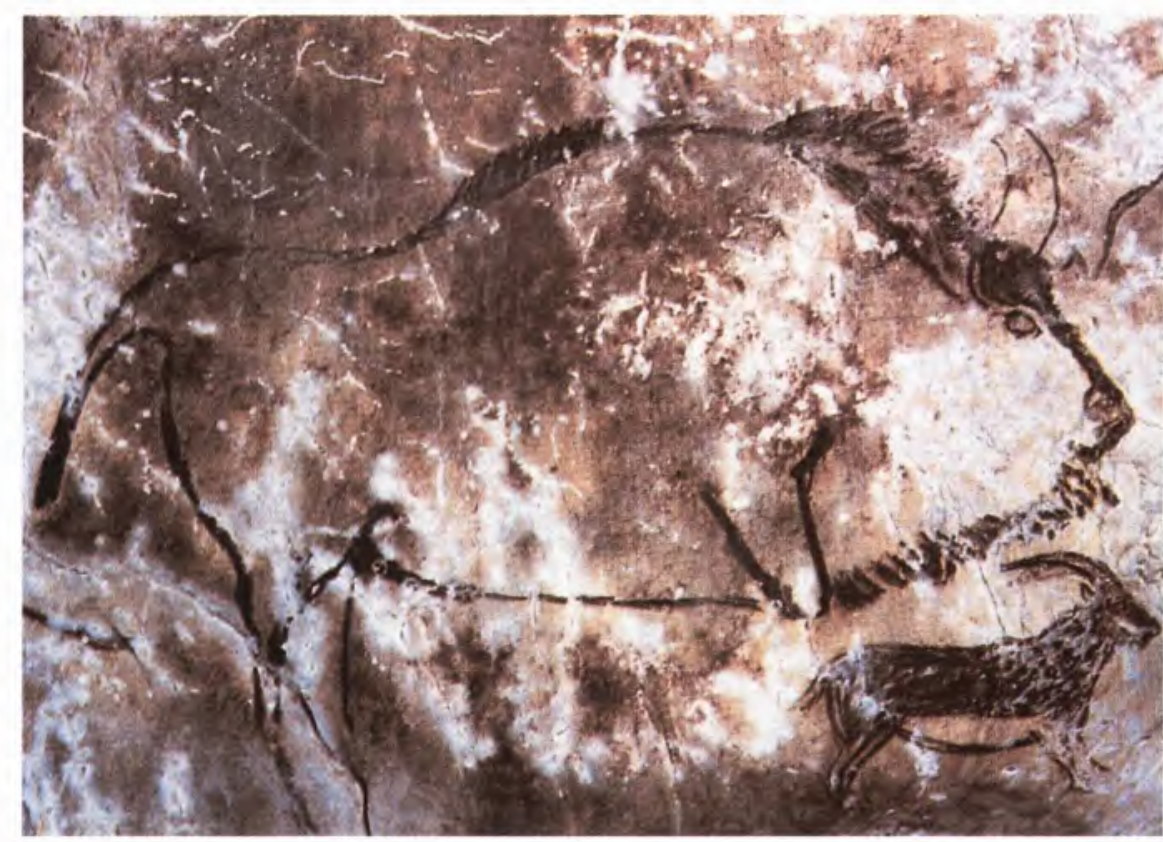

Fig. 5 - Pormenor do painel IV da Sala Negra. Gruta de Niaux.

afirmação, que as pinturas da Sala Negra da gruta de Niaux (Fig. 5) teriam sido feitas com uma mistura de carvão, óxido de manganês e gordura. Outros pré-historiadores admitiram ainda, com base em observações visuais efectuadas, que os pigmentos das pinturas de Altamira seriam de natureza variada nomeadamente ocres negros ou vermelhos, hematite, carvão, óxidos de manganês, negros ou violetas, e negro de fumo ou de osso.

\subsection{Exames físico-químicos da matéria pictural}

Deve notar-se todavia que, no referente às pinturas de Altamira, foi só a partir de 1977 que se começaram a fazer exames físico-químicos da matéria pictural com auxílio da microscopia óptica, da difracção de raios-X e da espectrografia de emissão $[8,9]$. Esses exames permitiram determinar a composição de várias amostras de pigmentos, quer achados em escavações efectuadas em 1924-1925 na entrada da gruta - alguns dos quais ainda dentro de conchas de lapas utilizadas pelos artistas - quer colhidos directamente do constituídos essencialmente pelas seguintes substâncias: os pigmentos vermelhos por hematite; os negros por carvão vegetal, carvão animal (pó de ossos, chifres ou dentes queimados) ou óxidos de manganês; os castanhos e amarelos igualmente por hematite mas agora acompanhada de goetite $(\alpha \mathrm{FeOOH})$ em proporção variável consoante a cor, aumentando no sentido do amarelo; o branco por uma mistura de uma argila micácea com quartzo; os cinzentos por co mas em que a mica é uma ilite com um grau de cristalinidade mais elevado. Verificou-se, além disso, que tanto os pigmentos vermelhos como os negros se apresentam misturados com quartzo e micas e, por vezes, com um mineral de origem orgânica - o âmbar - que talvez tivesse sido adicionado para exercer a função de aglutinante.

Por outro lado, no que respeita às pinturas da gruta de Lascaux (Fig. 6), os exames físico-químicos foram iniciados somente em 1979 [10, 11], fazendo uso de amostras de materiais recolhidos em escavações na gruta entre 1952 e 1963. Neste caso tecto, verificando-se que eles são uma mistura semelhante à do bran- verificou-se que os pigmentos vermelhos são constituídos por hematite, os negros sobretudo por óxidos de manganês e menos frequentemente por carvão vegetal, e os amarelos por goetite, encontrando-se todos eles sistematicamente associados a certos minerais, em geral quartzo mas também calcite e argila, o que foi interpretado pelos investigadores que realizaram as análises como resultando de uma acção deliberada dos artistas.

Mais tarde Vandiver [12] analisou outras amostras da gruta de Lascaux, mas agora colhidas directamente de pinturas, e comparou os resultados que obteve para elas com os obtidos quer na análise de materiais achados junto das paredes onde se encontravam as pinturas amostradas, quer na análise de algumas amostras geológicas. Pôde deste modo concluir que os artistas deveriam moer e misturar os minerais que entravam na composição da matéria pictural com o fim de controlar a cor e a sua fluidez. Refira-se que Vandi-

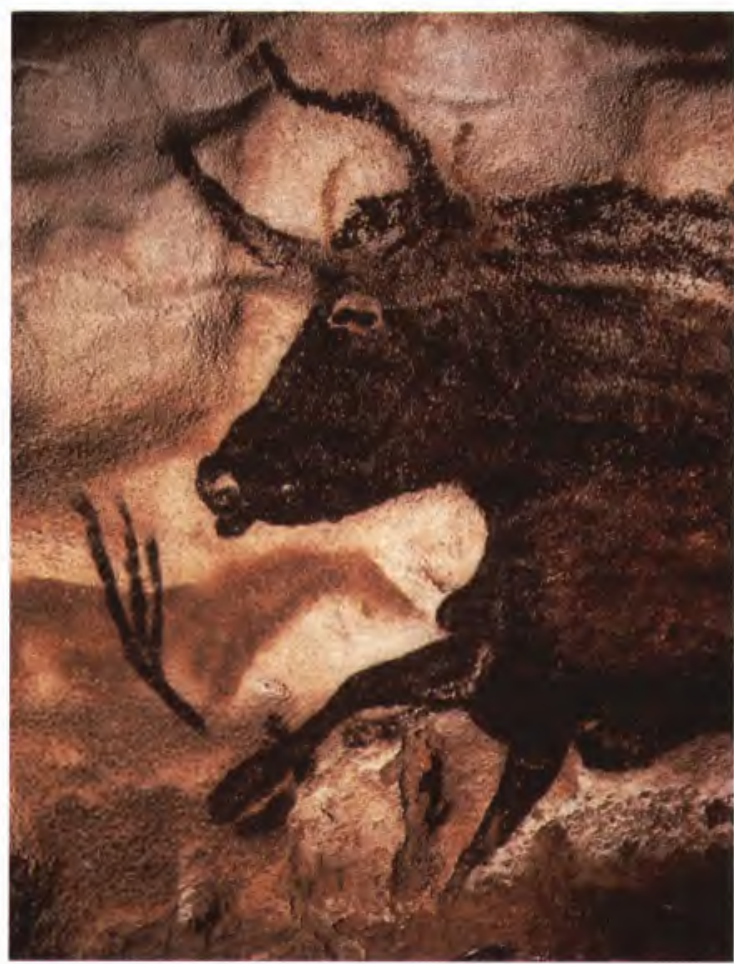

Fig. 6 - Auroque. Gruta de Lascaux. 
ver não se limitou apenas ao estudo das pinturas da gruta de Lascaux. Ela estudou também pinturas de outros sítios, designadamente da gruta de Renne, em Arcy-sur-Cure, e de diversas grutas no Ariège.

É interessante notar que exames efectuados no microscópio óptico a quatro amostras de pigmentos negros colhidas em fissuras existentes nas paredes da Sala Negra da gruta de Niaux, com o objectivo de determinar a sua natureza, revelaram que esses pigmentos eram de carvão de madeira de uma árvore resinosa. Exames mais pormenorizados efectuados depois no microscópio electrónico de varrimento (SEM), embora não tivessem sido inteiramente conclusivos, indicaram que a madeira que produziu esse carvão seria provavelmente de zimbro [13]. Por outro lado, análises realizadas em amostras de pigmentos negros da gruta de Quercy mostraram, umas vezes, a presença de carvão de madeira, outras vezes, a presença de carvão de osso [14]. Como se verá adiante, deve-se à presença de carvão vegetal ou animal em certos pigmentos a possibilidade de fazer a datação directa das pinturas.

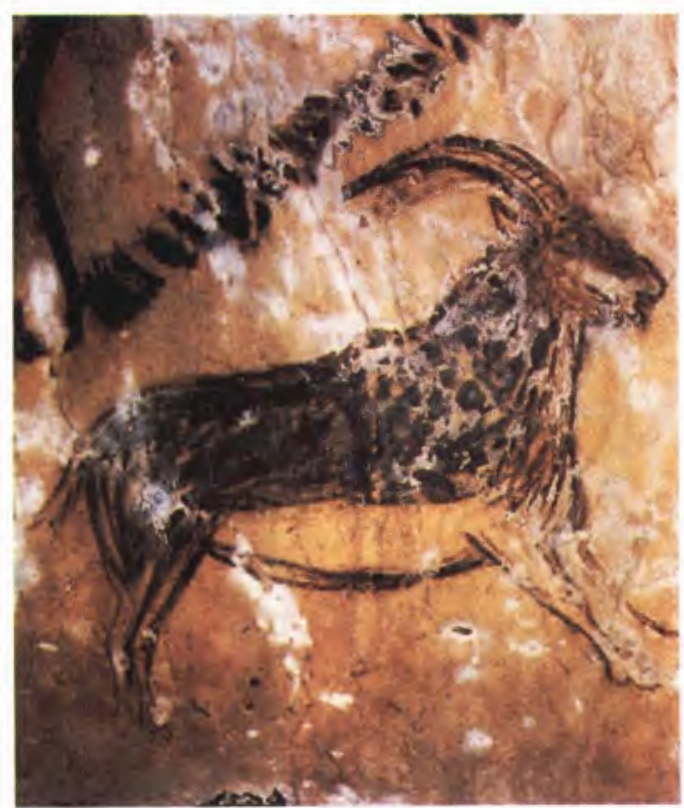

Fig. 7 - Cabrito-montês: pormenor do painel IV da Sala Grande. Gruta de Niaux.
Para a caracterização da matéria pictural em pinturas pré-históricas contribuíram ainda, nos anos 80 , vários outros investigadores [15-23], podendo dizer-se dum modo geral que os pigmentos utilizados na execução de tais pinturas - sobretudo pigmentos vermelhos e negros, mas também castanhos, amarelos e, nalguns casos, brancos - foram não só os já referidos atrás como ainda os ocres vermelhos e amarelos e, embora muito raramente, o guano de morcego.

Alguns estudos de caracterização visaram também a arte móvel, em particular a arte móvel gravada e pintada achada na gruta de La Vache (Ariège), cujo contexto, que se encontra convenientemente datado, é do Magdalenense superior. Neste caso, os objectos de arte foram examinados no SEM e os resultados obtidos mostraram, tal como havia sido verificado em estudos anteriores sobre a arte parietal, que os pigmentos vermelhos e negros utilizados nas pinturas deveriam ter sido misturados com certos minerais. Só que, agora, tornava-se evidente que as misturas teriam sido feitas de acordo com uma receita previamente estabelecida [24].

\subsection{Receitas de preparação da matéria pictural}

Mas será que os artistas pré-históricos se teriam guiado geralmente por fórmulas pré-estabelecidas para prepararem a matéria pictural de que se serviam nas suas pinturas? E, no caso afirmativo, teriam essas receitas variado com o tempo? Para responder a estas perguntas e a outras, como por exemplo a de saber se todas as pinturas da vastíssima gruta de Niaux constituiriam um só conjunto pictural - como pensavam Leroi-Gourhan e Vialou - ou se as pinturas das galerias, representando signos e raros animais, corresponderiam a uma lógica diferente da subjacente às representações naturalistas da Sala Negra - como admitia Clottes -, iniciou-se em França, na parte final dos anos 80 , um grande projec-

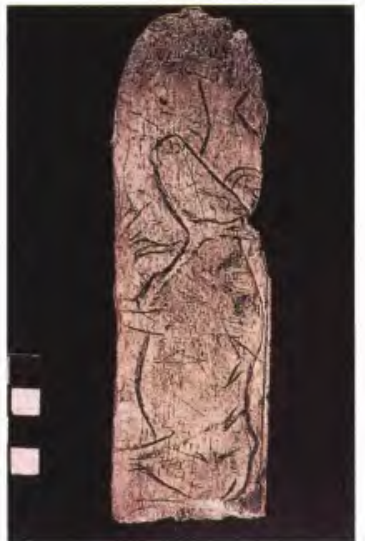

Fig. 8 - Gravura realçada com pintura negra, representando uma vaca e o seu vitelo. Gruta de Mas d'Azil.

to de investigação da pintura préhistórica achada nesse país envolvendo, por um lado, pré-historiadores e, por outro, investigadores do Laboratoire de Recherche des Musées de France. O trabalho experimental baseou-se num conjunto bastante grande de amostras, colhidas sobretudo em pinturas da Sala Negra e doutras galerias da gruta de Niaux e Réseau Clastres (Fig. 7), e ainda das grutas de Fontanet, Les Trois Frères e Le Portel, assim como numa série de amostras colhidas em pinturas sobre objectos de arte móvel achados nas grutas de La Vache, Enlène e Mas d'Azil (Fig. 8), amostras essas que se limitaram apenas aos vermelhos e negros num total de cerca de uma centena. Todas elas foram depois analisadas recorrendo ao SEM, à espectrometria de raios-X, à difracção de raios-X e aos métodos $\mathrm{PIXE}^{* * *}$ e PIGE**** de análise elementar $[25,26]$.

Tal como anteriormente, os resultados obtidos mostraram que tanto os pigmentos vermelhos (hematite) como os negros (carvão de madeira finamente moído ou óxido de manganês) se encontram nas respectivas amostras associados a certos minerais de cor pálida e a um aglutinante orgânico. Não foi possível, porém, neste caso determinar a natureza do aglutinante. Quanto aos minerais verificou-se que havia três variedades, uma das quais é da 
mesma natureza daquela que já havia sido identificada na matéria pictural presente nas obras de arte móvel da gruta de La Vache. São elas as seguintes:

- receita F - feldspato potássico, em grãos de forma ovóide por vezes com fracturas angulosas;

- receita $\mathrm{B}$ - feldspato potássico e biotite em plaquetas de cerca de 10 (m de comprimento;

- receita $\mathrm{T}$ - talco.

Em cada uma verificou-se ainda a presença sistemática de quartzo em pequenos grãos, o qual poderia já estar naturalmente associado aos minerais adicionados ou resultar da moagem desses minerais no caso de esta ter sido efectuada com um calhau de quartzo.

É importante notar que os minerais observados apresentam uma granulometria compreendida entre 10 e $30 \mu \mathrm{m}$, com raros grãos de tamanho maior que chega a ultrapassar $100 \mu \mathrm{m}$, e um grau de homogeneidade apreciável. Ora uma tal granulometria só muito excepcionalmente se encontra em produtos naturais. Por outro lado, a associação desses minerais com óxidos de ferro ou de manganês parece não ocorrer na natureza, nem a sua presença pode ser devida a qualquer poluição das paredes que servem de suporte às pinturas, dado que os mesmos minerais se encontram também associados àqueles pigmentos em objectos de arte móvel. Note-se, além disso, que análises efectuadas a um pedaço de matéria pictural achado em estratigrafia em níveis d'habitat da gruta de Enlène revelaram igualmente a associação de hematite com feldspatos potássicos.

Parece não haver dúvida, portanto, de que os referidos minerais devem ter sido intencionalmente adicionados aos diferentes pigmentos pelos artistas magdalenenses e cuidadosamente moidos e misturados até à obtenção de um bom grau de homogeneidade, talvez para facilitar a sua adesão às paredes ou aos objectos.

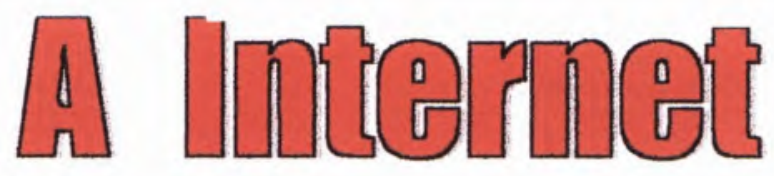

- Aumente produtividade

- Alargue o seu mercado

- Reduza despesas

(e use-a para fazer as compras de Natal!)
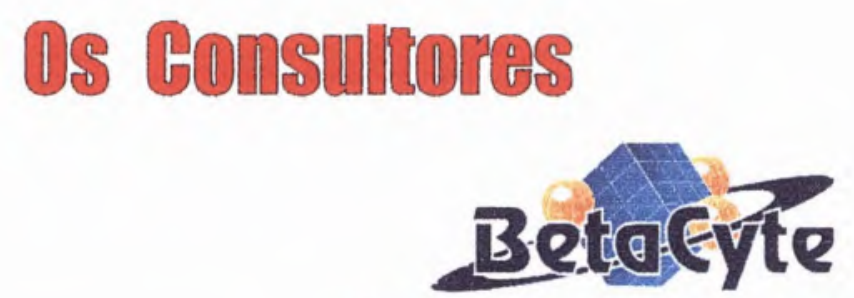

http://mww.betacyte.com

\begin{abstract}
Dr. Patrick M. van der Valk, Direcior
Kua Joáo Luis Kicardo 65, 4b Parede

lel: (01) 456.42.98 Fax: (01) 458.07.91

enaul: consult( $\omega$ betacyte.pt $\boldsymbol{o u}$ valk $(\omega)$ betacyte.com
\end{abstract}

\title{
A primeira consulta é grátis!
}

\subsection{Cronologia das receitas}

Para saber se as receitas de preparação da matéria pictural teriam variado com o tempo não basta determinar a sua composição. É necessário ainda conhecer a altura em que foram feitas, ou seja, é preciso datar as pinturas correspondentes.

A datação de pinturas pré-históricas era, até há pouco tempo, muito difícil de efectuar com rigor aceitável. O método que normalmente se empregava e ainda se utiliza, proposto e desenvolvido por pré-historiadores, baseia-se em critérios de estilo, i.e., no estabelecimento de uma sucessão cronológica de estilos. Trata-se, porém, de um método de datação relativa e, por isso, não é de estranhar que já tivesse conduzido a resultados contraditórios. No entanto, a sua combinação com o método do ${ }^{14} \mathrm{C}$, aplicado a vestígios de ocupação humana que por vezes têm sido achados próximo das pinturas, e, por outro lado, o facto de uma parte dos objectos de arte móvel terem sido encontrados em estratos com artefactos que podem datar-se mais rigorosamente, veio permitir realizar alguns progressos e aumentar a sua credibilidade. Apesar disso, a imprecisão que afecta os seus resultados, embora menor do que anteriormente, ainda se mantem grande, devido sobretudo à incerteza da pressuposta correlação entre as pin- 
Tabela 1 - Datas de ${ }^{14} \mathrm{C}$ de pigmentos de carvão vegetal ou animal, colhidos em pinturas parietais

\begin{tabular}{l} 
Gruta, localização e identificação da pintura \\
\hline Altamira \\
Parte central do tecto pintado (zona III na fig.133 ou fig.670)* \\
Pequeno bisonte voltado para o lado esquerdo: carvão (GifA 91178) \\
Grande bisonte voltado para o lado esquerdo: carvão (GifA 91179) \\
Grande bisonte voltado para o lado direito: carvão (GifA 91181) \\
Signo da galeria terminal: carvão (GifA 91185)
\end{tabular}

\section{El Castilho}

Parede próxima da entrada (zona IV Nos 18 e 19 na fig.139)*

Grande bisonte voltado para o lado direito: carvão (GifA 91004)

Grande bisonte voltado para o lado direito: carvão (GifA 91172)

\section{Niaux}

Sala Negra (painell na fig. 154)*

Grande bisonte voltado para o lado direito: carvão (GifA 91319)

Traço a carvão (GifA 92499)

Pequeno bisonte (?)

\section{Le Portel}

Cavalo do tipo de Niaux: carvão (AA 9465)

Grande cavalo precedendo o painel terminal: carvão (AA 9766)

\section{Covaciella}

Bisonte voltado para o lado direito (GifA 95281)

Bisonte voltado para o lado esquerdo (GifA 95364)

\section{Cosquer}

Mão negra: 1a metade da amostra (GifA 92409) 2a metade da amostra (GifA 92491)

Felino a traço negro (GifA 92418)

Cavalo a traço negro: 1ª metade da amostra (GifA 92416) $2^{3}$ metade da amostra (GifA 92417)

Bisonte negro: $1^{\mathrm{a}}$ metade da amostra (GifA 92419)

$$
2^{-} \text {metade da amostra (GifA 92492) }
$$

\section{Cougnac}

Painel VIII, pontuação digital negra (GifA 89250)

Painel IX, pontuação digital negra (GifA 92500)

Painel IV, Megaceros macho: bossa da cernelha (GifA 91183) cernelha e dorso (GifA 92426)

Painel IV, Megaceros fêmea: dorso (GifA 91324) bossa da cernelha e peitoral (GifA 92425)

\section{Pech Merle}

Cavalo voltado para a direita, painel dos cavalos picotados (GifA 95357)

\section{Chauvet-Pont-díArc}

Rinocerontes defrontados

rinoceronte voltado para o lado direito: alíquota a (GifA 95132) alíquota b (GifA 95133)

rinoceronte voltado para o lado esquerdo: (GifA 95126)

Grande bisonte do fundo (GifA 95128)

Resíduo de tocha, alíquota a (GifA 95129) alíquota b (GifA 95130)

Resíduo de tocha (GifA 95127)

$18010 \pm 190$
$12890 \pm 160$

$13060 \pm 200$

$13850 \pm 150$

$13570 \pm 190$

$13940 \pm 170$

$14330 \pm 190$

$15440 \pm 200$

$13060 \pm 200$ $12910 \pm 180$

$12180 \pm 125$

$11600 \pm 150$

$14060 \pm 140$

$14260 \pm 130$

$27110 \pm 390$

$27110 \pm 350$

$19200 \pm 220$

$18840 \pm 240$

$18820 \pm 310$

$18530 \pm 180$

$14290 \pm 180$

$13810 \pm 210$

$23610 \pm 350$

$22750 \pm 390$

$19500 \pm 270$

$25120 \pm 390$

$24640 \pm 390$

$32410 \pm 720$

$30790 \pm 600$

$30940 \pm 610$

$30340 \pm 570$

$26980 \pm 410$

$26980 \pm 420$

$26120 \pm 400$ turas que se procura datar e os vestígios achados na sua vizinhança. Na verdade, a experiência tem mostrado que os vestígios deixados pelos habitantes ou visitantes de cada gruta se estendem em regra por vários milénios [27].

Assim, e atendendo ao facto de a nova técnica de datação pelo radiocarbono - a técnica de AMS***** [28] - ter aberto a possibilidade de fazer datações com quantidades de carbono muito pequenas, da ordem de grandeza de 0,1-1 mg, tem-se procurado nestes últimos cinco anos datar directamente a matéria pictural. As primeiras datas obtidas deste modo, determinadas a partir de amostras de pigmentos negros de carvão vegetal colhidas em pinturas das grutas de Altamira, El Castillo e Niaux foram publicadas em 1992 [27]. Actualmente, já se conhecem 27 datas de pinturas parietais situadas em 9 grutas paleolíticas, obtidas directamente por AMS, as quais se apresentam na Tabela $1[2,29]$. É interessante notar que, apesar de as pinturas parietais da gruta de Lascaux serem umas das mais célebres pinturas pré-históricas, não foi ainda possível datá-las directamente em virtude de os artistas que as realizaram terem feito aí muito pouco uso de carvão vegetal ou animal como pigmento.

Note-se, além disso, que por enquanto não foram publicados mais resultados de datações directas de pinturas parietais pré-históricas localizadas em França e que, consequentemente, as informações disponíveis sobre datas referentes às pinturas das restantes galerias das grutas de Niaux e Réseau Clastres, bem como das grutas de Fontanet e Les Trois Frères, que constituiram a matéria de estudo do grande projecto de investigação atrás referido, se limitam a resultados de datações de ${ }^{14} \mathrm{C}$ de vestígios de ocupação humana achados nas proximidades dessas pinturas. Por outro lado, as informações disponíveis sobre datas respeitantes às pinturas das grutas de La Vache, Enlène e Mas d'Azil, que também fizeram parte desse estudo, 
provêm não só de datações de ${ }^{14} \mathrm{C}$ de vestígios de ocupação humana achados na vizinhança de pinturas parietais mas também de datações de objectos de arte móvel decorados, achados em estratos com carvões ou utensílios e armas de datas convenientemente estabelecidas e, portanto, de maior confiança.

Na Tabela 2 [26] mostram-se os resultados obtidos nos ensaios de identificação dos minerais associados aos pigmentos vermelhos e negros das pinturas das grutas estudadas, juntamente com a indicação da época em que tais pinturas teriam sido realizadas.

Os resultados apresentados na parte inferior da Tabela 2, relativos às pinturas sobre objectos de arte móvel achados em níveis arqueológicos bem datados, mostram que as receitas de minerais adicionados à matéria pictural parecem ter efectivamente variado com o tempo e possuir, portanto, um certo valor cronológico. Na verdade, verifica-se que a receita $\mathrm{F}$ corresponde às pinturas do Magdalenense médio e a receita $B$ às do Magdalenense superior.

Os apresentados na parte de cima da mesma tabela, referentes às pinturas parietais, embora não sejam tão sugestivos a esse respeito como os anteriores, estão em grande parte de acordo com eles, levando a crer que na gruta de Niaux haja pinturas quer do Magdalenense médio quer do Magdalenense superior. Estes resultados, embora de certo modo preliminares, permitiram a Clottes et allii. [26] chegar a conclusões muitíssimo interessantes que vieram pôr em causa as teorias clássicas sobre a criação do santuário de Niaux. Note-se que no que se refere às pinturas de Le Portel, os resultados ainda não foram publicados, mas já se deu a conhecer que eles parecem revelar o uso de outras receitas correspondendo a estilos considerados mais antigos.

É possível que a mudança de uma receita para outra, em certas alturas, tenha sido feita por motivos seja de natureza prática (esgotamento de fontes de matéria prima), seja de natureza técnica (melhoria do produto), seja de natureza económica (maior facilidáde de elaboração da pintura). Situações semelhantes vieram a verificarse também em diferentes épocas históricas, como por exemplo no séc.XV com o pigmento "amarelo de chumbo e de estanho", que até 1440 era fabricado na variedade II (apresentando uma composição heterogénea na qual se encontrava silício), provavelmente por mestres vidreiros, e que a partir daí passou a ser produzido sem perda de qualidade na variedade I (de composição homogénea e sem silício), por um processo mais simples e menos caro $[30,31]$.

\subsection{Desenho subjacente}

Outro resultado muito interessante obtido no mesmo projecto de investigação foi a descoberta, nalgumas amostras de pigmentos negros colhidas em pinturas da Sala Negra da gruta de Niaux, de fragmentos de carvão de madeira com o tamanho de cerca de $100 \mu \mathrm{m}$ subjacentes à matéria pictural, que neste caso é constituida por óxido de manganês misturado com uma das três qualidades de minerais atrás referidas. Repare-se que o facto de tais fragmentos terem aquela dimensão e serem de um material pouco duro leva a crer que o carvão de madeira presente nessas amostras não tenha sido moido juntamente com o óxido de

Tabela 2 - Minerais associados aos pigmentos vermelhos e negros de pinturas parietais das sete grutas por enquanto estudadas

\begin{tabular}{|c|c|c|c|}
\hline \multirow[t]{2}{*}{ Gruta } & \multicolumn{2}{|c|}{ Receita } & \multirow{2}{*}{$\begin{array}{c}\text { Contexto } \\
\text { Magdalenense }\end{array}$} \\
\hline & F $\quad$ B & $\mathbf{T}$ & \\
\hline $\begin{array}{l}\text { Niaux } \\
\text { Les Trois Frères } \\
\text { Fontanet } \\
\text { Le Portel }\end{array}$ & 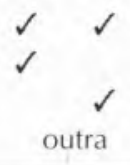 & $\checkmark$ & $\begin{array}{l}\text { médio ou superior } \\
\text { médio } \\
\text { médio ou superior } \\
\text { superior }\end{array}$ \\
\hline $\begin{array}{l}\text { La Vache } \\
\text { Enlène } \\
\text { Mas d'Azil - Péquart } \\
\text { Mas d'Azil - Piette }\end{array}$ & $\begin{array}{l}\checkmark \\
\checkmark\end{array}$ & & $\begin{array}{c}\text { superior } \\
\text { médio } \\
\text { médio } \\
\text { médio ou superior }\end{array}$ \\
\hline
\end{tabular}

manganês e os minerais adicionados - muito mais duros e de granulometria muito menor - e que, por isso, não devam fazer parte da matéria pictural.

Assim, a presença dos fragmentos de carvão de madeira detectados nestas amostras só pode ter uma interpretação - a de que eles pertencem a um desenho subjacente às pinturas amostradas, o qual teria sido traçado com um pedaço de madeira queimada. Aliás esta interpretação pôde depois ser confirmada examinando directamente essas pinturas à lupa binocular, e o mesmo veio a demonstrar-se em relação a todas as pinturas negras da Sala Negra que se encontravam acessíveis a este tipo de exame, com excepção das do grande cervo e da cabeça de cavalo na sua vizinhança, bem como das de dois pequenos cavalos sobrepostos na abóboda.

Parece, pois, que os artistas Magdalenenses já usavam técnicas de pintura para realizar as suas obras que, na sua essência, não diferiam grandemente das que mais tarde vieram a ser adoptadas pelos pintores dos tempos históricos. Com efeito, antes de aplicarem as camadas de cor, começavam por fazer um desenho preparatório. Além disso, misturavam os pigmentos com outros produtos para melhorar as propriedades da matéria pictural. Estes factos revelam bem o carácter deliberado e reflectido das obras de tais artistas. 


\subsection{Considerações finais}

Terminarei por fazer notar que, apesar das enormes dificuldades do ponto de vista analítico em detectar na matéria pictural as substâncias aglutinantes que porventura se teriam usado na sua preparação, uma das quais seria provavelmente a água, já foi possível em certos casos obter algumas informações sobre a sua natureza. Foi, por exemplo, o caso de pinturas em obras de arte móvel achadas na gruta de Enlène e de alguns motivos de pintura parietal da gruta de Les Trois Frères, onde se detectou a presença de gorduras vegetais com auxílio da cromatografia gasosa e da espectometria de massa. Foi também o caso de uma pintura parietal da gruta de Fontanet, na qual se verificou a presença de gordura animal recorrendo aos mesmos métodos instrumentais de análise [32]. Parece, pois, que na época Magdalenense alguns artistas já praticariam a pintura a óleo.

É interessante notar, além disso, que nas obras de arte do Paleolítico europeu não se encontraram por enquanto azuis nem verdes e que esta mesma característica se terá mantido durante vários milénios. Qual teria sido o motivo da sua exclusão? Incapacidade do homem pré-histórico de distinguir certas cores? Interdições de índole religiosa e cultural? Ou, simplesmente, uma diminuta disponibilidade de pigmentos dessas duas cores? O que parece mais razoável, pelo menos no que se refere aos pigmentos azuis, é que tivesse sido a sua fraca disponibilidade, já que a escassez de minerais de cor azul, utilizáveis como pigmentos, sempre se revelou uma característica constante ao longo do tempo até meados do século XIX.

\section{AGRADECIMENTOS}

Agradece-se reconhecidamente ao Doutor João Zilhão, Eng. Monge Soares e Enga . Isabel Ribeiro a amável cedência de informações bibliográficas.
* Instituto Tecnológico e Nuclear, Química, Estrada Nacional $N^{\circ}$ 10, 2686 Sacavém Codex

** Para exprimir as datas de ${ }^{14} \mathrm{C}$ convencionou-se que se deveria fixar para o início da escala do tempo o ano de 1950 d.C. (aquele em que Libby et allii. publicaram as primeiras datas de amostras com idades até então desconhecidas -, ao qual se deu o nome de "Presente"e se representou por P. As datas de ${ }^{14} \mathrm{C}$ passaram, por isso, a ser expressas na forma Before Present ou, simplesmente, BP. Note-se que, em virtude de um ano da escala de radiocarbono não corresponder exactamente a um ano de calendário, não é correcto converter as datas de ${ }^{14} \mathrm{C}$, expressas em anos BP, em datas expressas em anos a.C./d.C. subtraindo-lhes 1950. Para fazer a conversão é necessário recorrer a uma curva de calibração apropriada. Contudo, nenhuma curva de calibração estendida para além de cerca de 20000 $B P$ foi por enquanto obtida.

*** Iniciais de Particle Induced X-ray Emission **** Iniciais de Particle Induced Gamma-ray Emission

***** Iniciais de Accelerator Mass Spectrometry

\section{REFERÊNCIAS BIBLIOGRÁFICAS}

1. I. M. Chauvet, E. Brunel-Deschamps, C. Hillaire, La Découverte de la Grotte Chauvet à Vallon-Pont-d'Arc (Ardèche), Le Seuil, Paris, 1995.

2. I. Clottes, I. M. Chauvet, E. Brunel-Deschamps, C. Hillaire, I. P. Daugas, M. Arnold, H. Cachier, J. Evin, P. Fortin, C Oberlin, N. Tisnerat, H. Valladas, C.R. Acad. Sci. Paris 320, série lla (1995) 1133.

3. H. Valladas, I. L. Reyss, G. Valladas, O. Bar Yoseff, B. Vandermeersch, Nature 331 (1988) 614.

4. H. Moissan, C.R. Acad. Sci. Paris 134 (1902) 1536.

5. H. Moissan, C.R. Acad. Sci. Paris 136 (1903) 144.

6. G. Courty, Bull. et Mém. Soc. d'Anthropologie de Paris (1902) 481 .

7. E. Cartailhac, H. Breuil, L'Anthropologie 19 (1908) 14.

8. I. Marti, Informe sobre los estudios realizados en las Cuevas de Altamira, C.S.I.C., 1977.

9. I. M. Cabrera-Garrido, em Actes de la 5e reúnion triennale de I'ICOM, Zagreb, 1978, 1.

10. C. Couraud, A. Laming-Emperaire, em A. LeroiGourhan e J. Allain (Editores), Lascaux inconnu, Xlle supplément à Gallia Préhistoire, C.N.R.S., 1979, 153.

11. O. Ballet, A. Bocquet, R. Bouchez, I. M. D. Coey, A. Cornu, em A. Leroi-Gourhan e I. Allain (Editores), Lascaux inconnu, Xlle supplément à Gallia Préhistoire, C.N.R.S., 1979, 171.
12. P. Vandiver, Paleolithic pigments and processing, Master Science Thesis, Department of Material Science and Engineering, M.I.T., 1983.

13. I. Brunet, B. Callède, G. Orial, Studies in Conservation 27 (1982) 173.

14. M. Lorblanchet, M. Labeau, I. L. Vernet, Préhistoire quercinoise 3 (1988) 79.

15. C. Couraud, Bull. de la Soc. Préhistorique Française 80 (1983) 104.

16. C. Couraud, Bull. des Antiquités Nationales 16-17 (1984-1985) 79 .

17. C. Couraud, L'Anthropologie 82 (1988) 17.

18. M. Dauvois, em Congrès Préhistorique de France, XXI e session, vol. 2, Montauban-Cahors, 1979, 97

19. G. Onoratini, Bull. Mus. Nat. Marseille 45 (1985) 114

20. G. Perinet, G. Onoratini, Rev. d'Archéométrie 11 (1987) 49.

21. C. San-Juan, em L'Art des Objets au Paléolithique. Actes des colloques de la Direction du Patrimoine, 8 , 1990, 223.

22. C. San-Juan, Paléo 2 (1990) 229.

23. E. Anati, Boll. del Centro Camuno di Studi Preistorici 6 (1971) 83 .

24. D. Buisson, M. Menu, G. Pinçon, Ph. Walter, Bull. de la Soc. Préhistorique Française 86 (1989) 183.

25. I. Clottes, M. Menu, Ph. Walter, Rock Art Research 7 (1990) 21.

26. I. Clottes, M. Menu, Ph. Walter, Bull. de la Soc. Préhistorique Française $\mathbf{8 7}$ (1990) 170.

27. H. Valladas, H. Cachier, P. Maurice, F. Bernaldo de Quiros, J. Clottes, V.Cabrera Valdés, P. Uzquiano, M. Arnold, Nature 357 (1992) 68.

28. J. M. P. Cabral, Colóquio/Ciências, № 7 (1991) 58 ,

29. M. Lorblanchet, Les Grottes Ornées de la Préhistoire, Éditions Errance, Paris, 1995

30. E. Martin, A. R. Duval, Studies in Conservation 35 (1990) 117.

31. J. M. P. Cabral, Colóquio/Ciências, N0 16 (1995) 60.

32. C. Pepe et allii., citado por M. Lorblanchet em Les Grottes Ornées de la Préhistoire, Éditions Errance, Paris, 1995, 156 